\title{
Chapter 13 \\ The Clinical Value of Cardiac PET in Heart Failure
}

\author{
Chi-Lun Ko and Yen-Wen Wu
}

\begin{abstract}
Heart failure (HF) is a complex clinical syndrome that results from any structural or functional impairment of ventricular filling or ejection of blood [1]. Approximately 5 million patients in the USA and 15 million patients in Europe have HF. It is the leading cause of hospitalization in elderly people. Despite treatment advances, the mortality rate of HF has increased steadily. More patients are surviving myocardial infarction (MI) due to better standards of care, and consequently this may increase numbers of patients who subsequently develop HF. HF places a significant burden on patients, carers, and healthcare systems.

Limited progress has been made in identifying evidence-based, effective treatments for HF over the last decades. Potential contributors include an incomplete understanding of pathophysiology and poor matching of therapeutic mechanisms.

Positron emission tomography (PET), as a molecular imaging technique, with various tracers allows noninvasive evaluation of contractile function, myocardial perfusion, metabolism, and innervation. Molecular imaging approaches using PET could be further used to evaluate inflammation, angiogenesis, cell death, and ventricular remodeling. It could provide new insights on the chemotherapy-related cardiotoxicity and the roles of stem cell monitoring in living bodies for cell-based therapy from preclinical studies to clinical trials. In conclusion, cardiac PET is a promising tool to understand the physiologic consequences of HF, resulting in early detection of patients with $\mathrm{HF}$ at risk, improvement of risk stratification, and
\end{abstract}

\section{C.-L. Ko, MD}

Department of Nuclear Medicine, National Taiwan University Hospital Yun-Lin Branch, Yunlin County, Taiwan

Department of Nuclear Medicine, National Taiwan University Hospital and National Taiwan University College of Medicine, Taipei, Taiwan

Y.-W. Wu, MD, PhD (四)

Department of Nuclear Medicine, National Taiwan University Hospital and National Taiwan University College of Medicine, Taipei, Taiwan

Cardiology Division of Cardiovascular Medical Center, Far Eastern Memorial Hospital, No.21, Sec.2, Nanya S. Rd., Banciao Dist., New Taipei City 220, Taiwan

Department of Nuclear Medicine, Far Eastern Memorial Hospital, New Taipei City, Taiwan

National Yang-Ming University School of Medicine, Taipei, Taiwan

e-mail:wuyw0502@gmail.com 
therapeutic strategy planning and treatment response monitoring. Therefore, in order to give the readers a brief and concise overview, we will mainly review the latest advances in cardiac PET studies in heart failure.

Keywords Heart failure • Positron emission tomography • Myocardial perfusion • Myocardial metabolism • Neuroautonomic system

\subsection{Perfusion}

\subsubsection{Coronary Artery Disease (CAD) and Microvascular Dysfunction}

Patients presenting with HF are initially classified based on the etiology of their disease, i.e., ischemic or nonischemic cardiomyopathy. The diagnosis of HF is clear if prior MI is reliably documented. With the wide availability of single-photon emission computed tomography (SPECT) cameras and perfusion tracers, SPECT is currently the preferred imaging modality of cardiac radionuclide imaging with good diagnostic accuracy and prognostic significance.

PET provides better image quality because of higher spatial resolution, less scatter, and fewer attenuation artifacts and may be superior to SPECT with respect to imaging quality, interpretative confidence, and inter-reader agreement. In addition, PET allows quantitative measurement of myocardial perfusion (MP) and metabolism. Cardiac PET with perfusion tracers, such as $\left[{ }^{15} \mathrm{O}\right]$-water, $\left[{ }^{13} \mathrm{~N}\right]$-ammonia, ${ }^{82}$ rubidium, and $\left[{ }^{18} \mathrm{~F}\right]$-flurpiridaz [2], allows noninvasive and absolute assessment of regional and global myocardial blood flow (MBF) in $\mathrm{ml} / \mathrm{min} / \mathrm{g}$. In conjunction with stress, regional and global coronary flow reserve (CFR) can also be calculated, which is the ratio between MBF at peak stress and MBF at rest.

CFR measures not only vasodilator capacity but also endothelial reactivity of the coronary circulation, allowing noninvasive quantitative assessment for patients with diffuse coronary luminal narrowing or microvascular dysfunction.

Coronary microvascular dysfunction is highly prevalent among at-risk individuals and is associated with adverse outcomes regardless of sex, even in the absence of overt coronary atherosclerosis [3]. It may reflect the functional alteration of endothelium, such as hypertension, dyslipidemia, diabetes mellitus, smoking, obesity, or metabolic syndrome, or structural alteration of microangiopathy, myocardial fibrosis, or loss of capillaries. The portion of HF consists predominantly of older age and high prevalence of comorbidities. The systemic pro-inflammatory state may induce coronary endothelial inflammation, microvascular dysfunction, myocardial substrate shift, myocardial and interstitial fibrosis that contribute to high diastolic left ventricular stiffness, and HF development, even with preserved LVEF. The potential roles of myocardial perfusion abnormalities in subjects with cardiovascular risks, metabolic disease, and HF warrant further investigations.

In patients with CAD, a reduced CFR was shown to have prognostic implications, being a more sensitive predictor for cardiac death than was reduced left 
ventricular ejection fraction (LVEF). CFR in patients with CAD was found to be also reduced in areas supplied by non-stenotic vessels, suggesting a microvascular component. A recent study showed an association between global CFR and major adverse cardiovascular events (MACE) independently of angiographic CAD prognostic index (CADPI) [4]. This may attribute to diffuse atherosclerosis or microvascular dysfunction. In addition, global CFR also modified the effect of coronary revascularization in terms of event-free survival. These emphasize the utility of cardiac PET in patient risk stratification and the role in decision-making for coronary revascularization.

\subsubsection{Transplant Vasculopathy}

Cardiac allograft vasculopathy (CAV) is one of the leading causes of late mortality after heart transplantation. It is characterized by the diffuse concentric intima thickening of both epicardial and intramyocardial arteries, which is difficult to be assessed by traditional coronary angiogram. Intravascular ultrasound (IVUS) has been proposed to be the most sensitive method for diagnosis of early CAV. Due to the progressive and diffuse process involving the epicardial and microvascular coronary system, traditional stress myocardial perfusion SPECT frequently underestimates disease severity and extent in patients with CAV. With the absolutequantitative nature, PET provides a noninvasive way to deal with this problem. A good correlation was observed between plaque burden as determined by IVUS and CFR as assessed by ${ }^{13} \mathrm{~N}$-ammonia PET in recipients with normal coronary angiography findings. Quantitative measurement of myocardial flow using dynamic ${ }^{13} \mathrm{~N}$ ammonia PET is thus clinically feasible [5]. A recent study enrolled 140 posttransplant recipients with median follow-up of 18.2 months; the relative perfusion defects, mean myocardial flow reserve, and mean stress MBF using dipyridamole rubidium-82 PET were significant predictors of adverse outcome [6].

\subsection{Sympathetic Innervation}

Neurohormonal activation is considered as a compensatory mechanism in HF and maintains perfusion to the heart, yet in the meanwhile is also responsible for the progression of HF. From a long-term point of view, it is associated with cardiac remodeling, progressive impairment of ventricular function, symptoms, and lethal arrhythmia. Despite their critical role in regulation of the heart, local neurohormonal statuses of patients are not routinely and closely monitored in clinical practice. Innervation imaging may provide prognostic information as well as guide selection of therapies. Both a decreased cardiac $\left[{ }^{123} \mathrm{I}\right]$-meta-iodobenzylguanidine (MIBG) activity and an increased washout rate are indicative of a poor prognosis in patients with chronic heart failure [7]. Several PET tracers, including 
$\left[{ }^{11} \mathrm{C}\right]$-meta-hydroxyephedrine (HED), a norepinephrine analog, and $\left[{ }^{11} \mathrm{C}\right]-$ CGP12177, a beta-adrenoceptor antagonist, not only can be used to visualize global but also regional defects in myocardial sympathetic innervation. A pilot study enrolled 10 patients with dilated cardiomyopathy who underwent PET with $\left[{ }^{11} \mathrm{C}\right]-$ HED before, acutely and 3 months after cardiac resynchronization (CRT) [8]. It showed CRT improves cardiac sympathetic nerve activity in responders and seems to be more effective in those with functionally preserved neuroautonomic system.

Decreased cardiac beta-adrenoceptor density measured by $\left[{ }^{11} \mathrm{C}\right]-\mathrm{CGP} 12177$ PET was observed in a study of patients with nonischemic cardiomyopathy. In addition the receptor density was significantly correlated with systolic function [9]. Receptor density correlated with $\left.{ }^{123} \mathrm{I}\right]-\mathrm{MIBG}$ washout rate and delayed heartto-mediastinum (H/M) ratio, but not early $\mathrm{H} / \mathrm{M}$ ratio. Another study showed that reduced myocardial beta-adrenoceptor density measured by $\left[{ }^{11} \mathrm{C}\right]-\mathrm{CGP} 12177$ early after myocardial infarction is associated with the incidence of congestive heart failure on long-term follow-up [10]. Besides $\left[{ }^{11} \mathrm{C}\right]$-labeled tracers, $\left[{ }^{18} \mathrm{~F}\right]-\mathrm{N}$ [3-Bromo-4-(3-fluoro-propoxy)-benzyl]-guanidine (LMI1195), an ${ }^{18} \mathrm{~F}$-labeled ana$\log$ of $\left[{ }^{123} \mathrm{I}\right]-$ MIBG SPECT agent, is a new PET tracer retained in the heart through the norepinephrine transporter (NET) and allowing evaluation of the cardiac sympathetic neuronal function by PET imaging [11-13].

\subsection{Noninvasive Assessment of Myocardial Metabolism}

\subsubsection{Myocardial Viability}

Myocardial viability, the evaluation of dysfunctional but viable myocardium, can be assessed by several imaging techniques. In conjunction with dobutamine, contractile reserve can be evaluated by either echocardiography or cardiac magnetic resonance imaging (MRI). Delayed contrast-enhanced (DCE) MRI and contrastenhanced CT can assess scar tissue. Myocardial perfusion SPECT evaluates either cell membrane or mitochondria integrity. $\left[{ }^{18} \mathrm{~F}\right]$-fluorodeoxyglucose (FDG) can be used to assess glucose metabolism and to differentiate the hibernating myocardium from scar tissue. Dual-isotope simultaneous acquisition (DISA) viability testing, the combination of $\left[{ }^{99 \mathrm{~m}} \mathrm{Tc}\right]$-sestamibi and $\left[{ }^{18} \mathrm{~F}\right]$-FDG SPECT, provides more accurate prediction of post-revascularization functional recovery than thallium-201 [14]. PET using FDG remains the most reliable and noninvasive tool to assess myocardial viability [15] and tends to replace Tl-201 SPECT imaging in centers equipped with a PET/CT camera.

For patients with CAD-associated chronic LV dysfunction, noninvasive detection of myocardial viability is crucial for decision-making of the treatment. Myocardial viability imaging can be used to inform the often difficult clinical decision regarding revascularization in patients with $\mathrm{CAD}$ and left ventricular systolic dysfunction, providing data on the potential benefit to balance against the known risks [15]. FDG PET has a higher sensitivity than DCE MRI, but comparable 
specificity, in predicting functional recovery [16]. The post hoc subgroup analysis of the PET and Recovery Following Revascularization (PARR-2) trial suggested that FDG PET-guided management reduces the composite of cardiovascular events in patients with ischemic cardiomyopathy in a center with an experienced imaging team [17].

Despite that several studies have emphasized the utility of viability imaging in identifying patients who may benefit from revascularization, a recent meta-analysis shows confusing results [18]. Patients with viable myocardium appear to benefit from revascularization, but the same benefits were observed in patients without viable myocardium. Some suggested this might be resulted from mixed traditional (SPECT and dobutamine echocardiography) and the advanced (MRI and PET) imaging techniques, but this was still not conclusive [19, 20]. A large prospective randomized trial regarding Alternative Imaging Modalities in Ischemic Heart Failure (AIMI-HF) has conducted in 2013 [21], which will complement the results of the Surgical Treatment for Ischemic Heart Failure (STICH) viability substudy and the PET and PARR-2 trial to answer this unsolved issue.

\subsubsection{Cardiac Efficiency}

$\left[{ }^{11} \mathrm{C}\right]$-acetate, a well-known myocardial PET tracer, is directly metabolized into $\left[{ }^{11} \mathrm{C}\right]$-acetyl-CoA in mitochondria and enters the Krebs cycle. $\left[{ }^{11} \mathrm{C}\right]$-acetate PET imaging provides noninvasive and reproducible measurements of cardiac oxidative metabolism $\left(\mathrm{MVO}_{2}\right)$ [22]. Heterogeneously decreased oxidative metabolism was observed in patients with ischemic and nonischemic cardiomyopathy [23]. In chronic HF MI porcine model, myocardial perfusion and oxygen consumption in the remote non-infarcted myocardium were preserved in HF pigs as compared to controls. Global LV work and efficiency were significantly lower in HF than controls and were associated with increased wall stress [24]. It can also be used to evaluate cardiac efficiency under variable conditions, especially after treatments of heart failure. Surgical intervention with LV volume reduction and mitral regurgitation correction significantly improved cardiac efficiency in patients with end-stage heart failure, which is observed in both nonischemic and ischemic etiologies [25].

On the other hand, myocardial oxygen metabolism was increased in patients with aortic stenosis (AS), which was decreased after aortic valve replacement [26]. It is suggested that the increased myocardial oxidative metabolism in AS was largely attributable to the pressure overload of the left ventricle and normalized after unload.

In a study of diastolic heart failure patients, decreased cardiac efficiency is associated with increased LV filling pressure but does not primarily cause diastolic dysfunction or diastolic heart failure in normal hearts [27]. They suggest that improvement of cardiac efficiency may be a target for the treatment of heart failure with preserved ejection fraction (HFpEF). 


\subsubsection{Cardiac Resynchronization Therapy (CRT)}

CRT can correct cardiac dyssynchrony and augment LV systolic function. PET is the only noninvasive imaging technique that can provide information on alternations of myocardial blood flow, glucose utilization, and oxygen consumption. $\left[{ }^{11} \mathrm{C}\right]-$ acetate PET can also be used to evaluate the efficacy of CRT in patients with severe heart failure [8, 28-31]. CRT could improve cardiac systolic function, but global resting $\mathrm{MBF}$ and global $\mathrm{MVO}_{2}$ are not always altered by CRT, even under stress condition [28]. A more homogeneous myocardial glucose uptake was observed, which implies CRT may induce a more balanced wall stress and energy requirement. Another study demonstrated that decreased oxygen consumption was observed in patients showing good response to CRT. The decrease in oxygen consumption assessed by PET in the early period after CRT is useful to predict improvement of cardiac function and major cardiac events during the first year of follow-up [31].

\subsubsection{Chemotherapy-Related Heart Failure}

$\left[{ }^{11} \mathrm{C}\right]$-acetoacetate, a ketone body tracer, is expected to have some similarities to $\left[{ }^{11} \mathrm{C}\right]$-acetate. In mitochondria, acetoacetate is first converted into acetoacetyl-CoA and then into acetyl-CoA. In cytoplasm, acetoacetate can also be directly incorporated into the lipogenesis pathway. Contrary to $\left[{ }^{11} \mathrm{C}\right]$-acetate and other MBF PET tracers, $\left[{ }^{11} \mathrm{C}\right]$-acetoacetate together with dynamic gated PET imaging was able to identify doxorubicin-induced heart failure at an early stage in a resting state. Thus, $\left[{ }^{11} \mathrm{C}\right]$-acetoacetate is promising for the assessment of cardiomyopathy [32].

\subsubsection{Metabolic Therapy}

Heart failure severity, substrate availability, hormonal status, and coexisting insulin resistance contribute to the metabolic change. Optimizing myocardial energy metabolism has been studied as a novel form of therapy [33]. Metabolic therapy is a promising new avenue for the treatment of heart failure. Suitable targets for therapy include substrate utilization, oxidative phosphorylation, and the availability of high-energy phosphates [34].

Insulin resistance is a recognized phenomenon leading to heart failure. The change in myocardial metabolism can be visualized using PET with metabolic tracers. A prospective study utilized $\left[{ }^{15} \mathrm{O}\right]$-water, $\left[{ }^{11} \mathrm{C}\right]$-acetate, $\left[{ }^{11} \mathrm{C}\right]$-glucose, and $\left[{ }^{11} \mathrm{C}\right]$-palmitate PET studies and found that obesity and gender independently modulate $\mathrm{MBF}$ and $\mathrm{MVO}_{2}$. Moreover, gender and obesity may interact in predicting myocardial glucose uptake and insulin sensitivity [35]. FDG PET can also be used in evaluation of the effect of therapy on glucose metabolism. In a transgenic mice model, $\mathrm{G}$ protein-coupled receptor kinase 2 inhibition delays the reduction in glucose uptake and protects insulin signaling in the heart, preserving cardiac dimension and function [36]. 


\subsection{Molecular Imaging Approaches of Cardiac Remodeling}

\subsubsection{Imaging of Matrix Metalloproteinases}

The matrix metalloproteinases (MMPs) play a role in physiologic extracellular matrix (ECM) turnover and response to cardiac disease. During the progression of HF, the level of MMPs is increased. The excessive degradation of ECM may result in wall thinning, dilatation, and heart failure. Post-MI myocardial LV remodeling is also associated with changes within the myocardial extracellular matrix and often leads to heart failure. MI results in the activation of the reninangiotensin-aldosterone system, which in turn results in the activating of MMPs within the heart. Molecular imaging of MMPs has the potential to allow early and serial evaluation of underlying alterations that accompany progression of LV remodeling [37]. The activation of MMPs in infarcted murine myocardium can be imaged by [ $\left.{ }^{111} \mathrm{In}\right]$ - and [ $\left.{ }^{99 \mathrm{~m}} \mathrm{Tc}\right]$-labeled single-photon ligands [38]. Several PET tracers have also been synthesized [39]. However, to date there are only limited publications, especially in the field of HF.

\subsubsection{Angiogenesis}

Angiogenesis occurs in response to ischemia and inflammation being part of the healing process after ischemic tissue injury. $\left[{ }^{18} \mathrm{~F}\right]$-galacto-RGD allows noninvasive imaging of the expression of $\alpha_{\mathrm{v}} \beta_{3}$ integrin that is highly expressed in the endothelium of angiogenic vessels. Noninvasive imaging using $\left[{ }^{18} \mathrm{~F}\right]$-galacto-RGD PET appears promising for the monitoring of therapies aiming to stimulate angiogenesis in ischemic heart disease and preventing the development of HF [40].

\subsubsection{Myocardial Inflammation}

FDG PET may be useful in the study of inflammatory process since inflammatory cells accumulate glucose. However, a recent study showed some limitations to study the inflammatory process after myocardial infarction even when active uptake of FDG in normal myocardial tissue is suppressed. In the presence of large region of microvascular obstruction, FDG may not reliably and accurately represent the degree of inflammatory cell activity. Even in areas without microvascular obstruction, the degree of inflammation may be underestimated or even overestimated [41].

Besides the usefulness as a molecular target for neuroendocrine tumor imaging, some of the somatostatin receptors are also expressed by activated macrophage. A recent animal study compared $\left[{ }^{68} \mathrm{Ga}\right]$-citrate, $\left[{ }^{68} \mathrm{Ga}\right]$-DOTATATE, and $\left[{ }^{18} \mathrm{~F}\right]-\mathrm{FDG}$ 
in a postinfarction mouse model [42]. They conclude that FDG with myocardial suppression is the most practical imaging marker of postinfarction inflammation. However, there are also some studies in human that emphasize the usefulness of the somatostatin receptor imaging in the assessment of sarcoidosis [43] and infarction [44]-related myocardial inflammation. Compared with the nonspecific FDG, this is a new potential biomarker that may be useful in evaluation of myocardial inflammation and predicting cardiac remodeling and progression toward heart failure.

\subsection{Conclusions}

Advances in the application of cardiac PET may play an increasingly critical role in diagnosis, prognosis, and clinical treatment of cardiovascular diseases. Molecular imaging approaches using PET could evaluate myocardial pathophysiology at different stages of HF. It further provides insights on the HF preventive strategies, tracking patients' clinical status, novel drug therapies, expanding indications for HF therapeutic devices, and gene or cell-based therapies (Fig. 13.1 and Table 13.1).

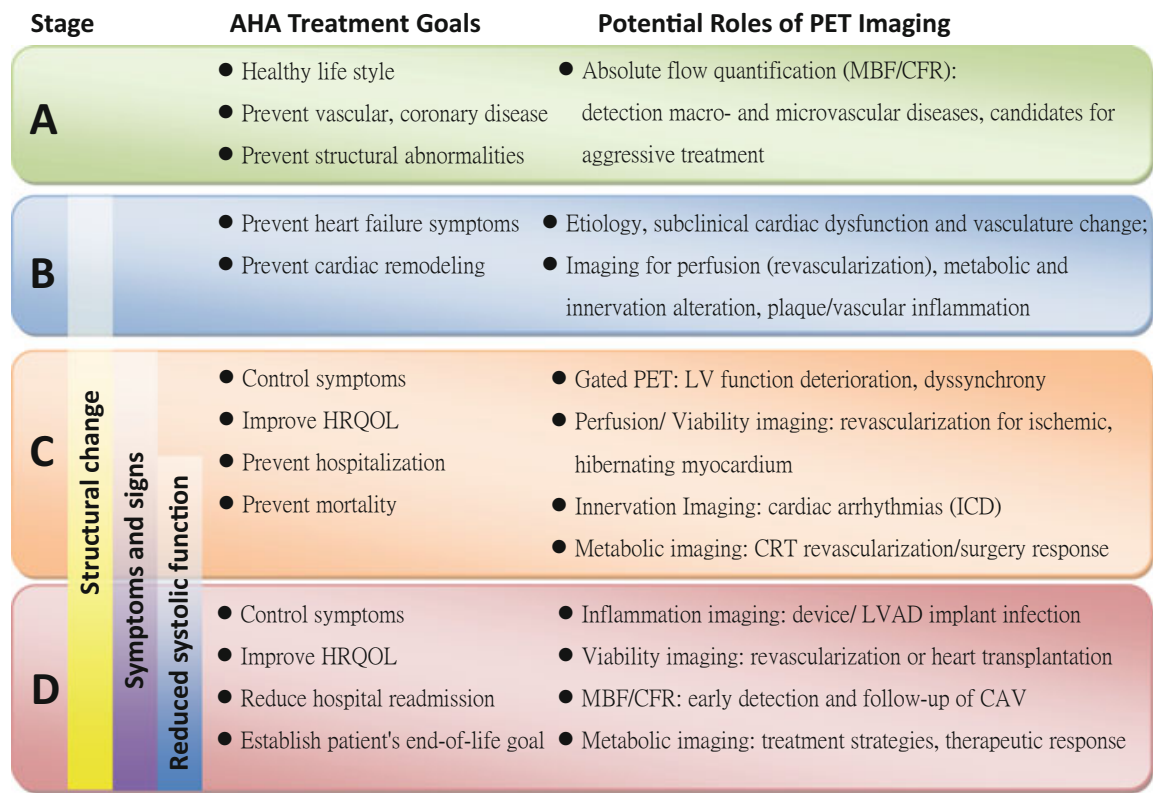

Fig. 13.1 Potential roles of PET imaging in different stages of American College of Cardiology (ACC)/American Heart Association (AHA) classification of heart failure. $C A V$ cardiac allograft vasculopathy, $C F R$ coronary flow reserve, $H R Q O L$ health-related quality of life, $I C D$ implantable cardioverter defibrillator, $M B F$ myocardial blood flow, $L V$ left ventricular, $L V A D$ left ventricular assist device 
Table 13.1 Examples of PET tracers useful in heart failure patients [12, 37, 39]

\begin{tabular}{l|l}
\hline Substrate & \\
\hline Flucose & ${ }^{18} \mathrm{~F}$-fluorodeoxyglucose \\
\cline { 2 - 2 } & ${ }^{11} \mathrm{C}$-glucose \\
\hline Oxidative metabolism & ${ }^{11} \mathrm{C}$-palmitate \\
\hline Apoptosis & ${ }^{18} \mathrm{~F}$-fluoro-6-thiaheptadecanoic acid \\
\hline Interstitial fibrosis & ${ }^{11} \mathrm{C}$-acetate \\
\hline Angiotensin-converting enzyme & ${ }^{18} \mathrm{~F}$-annexin $\mathrm{V}$ \\
\hline Angiotensin II type 1 receptor & \\
\hline Matrix metalloproteinase & ${ }^{18} \mathrm{~F}$-captopril, ${ }^{18} \mathrm{~F}-$ fluorobenzyl-lisinopril \\
\hline Sympathetic innervation & ${ }^{11} \mathrm{C}$-MK-996, ${ }^{11} \mathrm{C}-\mathrm{L}-159884,{ }^{11} \mathrm{C}-\mathrm{KR} 31173$ \\
\hline Presynaptic & ${ }^{18} \mathrm{~F}$-FB-ML5 \\
\cline { 2 - 2 } & ${ }^{11} \mathrm{C}$-labeled compounds \\
\hline Postsynaptic & \\
\hline Parasympathetic innervation & ${ }^{11} \mathrm{C}$-meta-hydroxyephedrine (HED) \\
\hline Acetylcholine transporter & ${ }^{18} \mathrm{~F}$-fluorodopamine \\
\hline & ${ }^{11} \mathrm{C}$-epinephrine \\
\hline Nicotinic receptor & ${ }^{11} \mathrm{C}$-CGP $12177 / 12388$ \\
\hline & ${ }^{18} \mathrm{~F}$-fluorocarazolol \\
\hline Muscarinic receptor & \\
\hline & ${ }^{18} \mathrm{~F}$-fluoroethoxybenzovesamicol \\
\hline${ }^{18} \mathrm{~F}$-fluoro-A85380 \\
\hline${ }^{11} \mathrm{C}$-methylquinuclidiny benzilate
\end{tabular}

Open Access This chapter is distributed under the terms of the Creative Commons AttributionNoncommercial 2.5 License (http://creativecommons.org/licenses/by-nc/2.5/) which permits any noncommercial use, distribution, and reproduction in any medium, provided the original author(s) and source are credited.

The images or other third party material in this chapter are included in the work's Creative Commons license, unless indicated otherwise in the credit line; if such material is not included in the work's Creative Commons license and the respective action is not permitted by statutory regulation, users will need to obtain permission from the license holder to duplicate, adapt or reproduce the material.

\section{References}

1. Yancy CW, Jessup M, Bozkurt B, Butler J, Casey Jr DE, Drazner MH, et al. 2013 ACCF/AHA guideline for the management of heart failure: a report of the American College of Cardiology Foundation/American Heart Association Task Force on Practice Guidelines. J Am Coll Cardiol. 2013;62(16):e147-239. doi:10.1016/j.jacc.2013.05.019.

2. Packard RR, Huang SC, Dahlbom M, Czernin J, Maddahi J. Absolute quantitation of myocardial blood flow in human subjects with or without myocardial ischemia using dynamic 
flurpiridaz F 18 PET. J Nucl Med: Off Publ Soc Nucl Med. 2014;55(9):1438-44. doi:10.2967/ jnumed.114.141093.

3. Murthy VL, Naya M, Taqueti VR, Foster CR, Gaber M, Hainer J, et al. Effects of sex on coronary microvascular dysfunction and cardiac outcomes. Circulation. 2014;129 (24):2518-27. doi:10.1161/circulationaha.113.008507.

4. Taqueti VR, Hachamovitch R, Murthy VL, Naya M, Foster CR, Hainer J, et al. Global coronary flow reserve is associated with adverse cardiovascular events independently of luminal angiographic severity and modifies the effect of early revascularization. Circulation. 2015;131(1):19-27. doi:10.1161/circulationaha.114.011939.

5. Wu YW, Chen YH, Wang SS, Jui HY, Yen RF, Tzen KY, et al. PET assessment of myocardial perfusion reserve inversely correlates with intravascular ultrasound findings in angiographically normal cardiac transplant recipients. J Nucl Med: Off Publ Soc Nucl Med. 2010;51 (6):906-12. doi:10.2967/jnumed.109.073833.

6. Mc Ardle BA, Davies RA, Chen L, Small GR, Ruddy TD, Dwivedi G, et al. Prognostic value of rubidium-82 positron emission tomography in patients after heart transplant. Circ Cardiovasc Imaging. 2014;7(6):930-7. doi:10.1161/circimaging.114.002184.

7. Kuwabara Y, Tamaki N, Nakata T, Yamashina S, Yamazaki J. Determination of the survival rate in patients with congestive heart failure stratified by (1)(2)(3)I-MIBG imaging: a metaanalysis from the studies performed in Japan. Ann Nucl Med. 2011;25(2):101-7. doi:10.1007/ s12149-010-0452-0.

8. Martignani C, Diemberger I, Nanni C, Biffi M, Ziacchi M, Boschi S, et al. Cardiac resynchronization therapy and cardiac sympathetic function. Eur J Clin Investig. 2015;45(8):792-9. doi:10.1111/eci.12471.

9. Tsukamoto T, Morita K, Naya M, Inubushi M, Katoh C, Nishijima K, et al. Decreased myocardial beta-adrenergic receptor density in relation to increased sympathetic tone in patients with nonischemic cardiomyopathy. J Nucl Med: Off Publ Soc Nucl Med. 2007;48 (11):1777-82. doi:10.2967/jnumed.107.043794.

10. Gaemperli O, Liga R, Spyrou N, Rosen SD, Foale R, Kooner JS, et al. Myocardial betaadrenoceptor down-regulation early after infarction is associated with long-term incidence of congestive heart failure. Eur Heart J. 2010;31(14):1722-9. doi:10.1093/eurheartj/ehq138.

11. Yu M, Bozek J, Lamoy M, Guaraldi M, Silva P, Kagan M, et al. Evaluation of LMI1195, a novel 18F-labeled cardiac neuronal PET imaging agent, in cells and animal models. Circ Cardiovasc Imaging. 2011;4(4):435-43. doi:10.1161/circimaging.110.962126.

12. Werner RA, Rischpler C, Onthank D, Lapa C, Robinson S, Sammnick S, et al. Retention Kinetics of the 18F-labeled Sympathetic Nerve PET Tracer LMI1195: Comparison with 11C-HED and 123I-MIBG. J Nucl Med: Off Publ Soc Nucl Med. 2015. doi:10.2967/ jnumed.115.158493.

13. Chen X, Werner RA, Javadi MS, Maya Y, Decker M, Lapa C, et al. Radionuclide imaging of neurohormonal system of the heart. Theranostics. 2015;5(6):545-58. doi:10.7150/thno.10900.

14. Wu YW, Huang PJ, Lee CM, Ho YL, Lin LC, Wang TD, et al. Assessment of myocardial viability using F-18 fluorodeoxyglucose/Tc-99m sestamibi dual-isotope simultaneous acquisition SPECT: comparison with Tl-201 stress-reinjection SPECT. J Nucl Cardiol. 2005;12 (4):451-9. doi:10.1016/j.nuclcard.2005.04.007.

15. Schinkel AF, Poldermans D, Elhendy A, Bax JJ. Assessment of myocardial viability in patients with heart failure. J Nucl Med: Off Publ Soc Nucl Med. 2007;48(7):1135-46. doi:10.2967/ jnumed.106.038851.

16. Allman KC, Shaw LJ, Hachamovitch R, Udelson JE. Myocardial viability testing and impact of revascularization on prognosis in patients with coronary artery disease and left ventricular dysfunction: a meta-analysis. J Am Coll Cardiol. 2002;39(7):1151-8.

17. Abraham A, Nichol G, Williams KA, Guo A. deKemp RA, Garrard L et al. 18F-FDG PET imaging of myocardial viability in an experienced center with access to 18F-FDG and integration with clinical management teams: the Ottawa-FIVE substudy of the PARR 2 trial. J Nucl Med: Off Publ Soc Nucl Med. 2010;51(4):567-74. doi:10.2967/jnumed.109.065938. 
18. Orlandini A, Castellana N, Pascual A, Botto F, Cecilia Bahit M, Chacon C, et al. Myocardial viability for decision-making concerning revascularization in patients with left ventricular dysfunction and coronary artery disease: a meta-analysis of non-randomized and randomized studies. Int J Cardiol. 2015;182:494-9. doi:10.1016/j.ijcard.2015.01.025.

19. Srichai MB, Jaber WA. Viability by MRI or PET would have changed the results of the STICH trial. Prog Cardiovasc Dis. 2013;55(5):487-93. doi:10.1016/j.pcad.2013.01.005.

20. Asrani NS, Chareonthaitawee P, Pellikka PA. Viability by MRI or PET would not have changed the results of the STICH trial. Prog Cardiovasc Dis. 2013;55(5):494-7. doi:10. 1016/j.pcad.2012.09.004.

21. O’Meara E, Mielniczuk LM, Wells GA. deKemp RA, Klein R, Coyle D et al. Alternative Imaging Modalities in Ischemic Heart Failure (AIMI-HF) IMAGE HF Project I-A: study protocol for a randomized controlled trial. Trials. 2013;14:218. doi:10.1186/1745-6215-14218.

22. Nesterov SV, Turta O, Han C, Maki M, Lisinen I, Tuunanen H, et al. C-11 acetate has excellent reproducibility for quantification of myocardial oxidative metabolism. Eur Heart J Cardiovasc Imaging. 2015;16(5):500-6. doi:10.1093/ehjci/jeu289.

23. Wu YW, Naya M, Tsukamoto T, Komatsu H, Morita K, Yoshinaga K, et al. Heterogeneous reduction of myocardial oxidative metabolism in patients with ischemic and dilated cardiomyopathy using C-11 acetate PET. Circ J: Off J Jpn Circ Soc. 2008;72(5):786-92.

24. Tarkia M, Stark C, Haavisto M, Kentala R, Vahasilta T, Savunen T, et al. Cardiac remodeling in a new pig model of chronic heart failure: Assessment of left ventricular functional, metabolic, and structural changes using PET, CT, and echocardiography. J Nucl Cardiol. 2015. doi:10.1007/s12350-015-0068-9.

25. Sugiki T, Naya M, Manabe O, Wakasa S, Kubota S, Chiba S, et al. Effects of surgical ventricular reconstruction and mitral complex reconstruction on cardiac oxidative metabolism and efficiency in nonischemic and ischemic dilated cardiomyopathy. J Am Coll Cardiol Img. 2011;4(7):762-70. doi:10.1016/j.jcmg.2011.04.010.

26. Naya M, Chiba S, Iwano H, Yamada S, Katoh C, Manabe O, et al. Myocardial oxidative metabolism is increased due to hemodynamic overload in patients with aortic valve stenosis: assessment using 11C-acetate positron emission tomography. Eur J Nucl Med Mol Imaging. 2010;37(12):2242-8. doi:10.1007/s00259-010-1540-z.

27. Hasegawa S, Yamamoto K, Sakata Y, Takeda Y, Kajimoto K, Kanai Y, et al. Effects of cardiac energy efficiency in diastolic heart failure: assessment with positron emission tomography with 11C-acetate. Hypertens Res. 2008;31(6):1157-62. doi:10.1291/hypres.31.1157.

28. Henneman MM, van der Wall EE, Ypenburg C, Bleeker GB, van de Veire NR, Marsan NA, et al. Nuclear imaging in cardiac resynchronization therapy. J Nucl Med: Off Publ Soc Nucl Med. 2007;48(12):2001-10. doi:10.2967/jnumed.107.040360.

29. Ypenburg C, Bax JJ. The role of positron emission tomography in evaluation of alterations in cardiac efficiency after cardiac resynchronization therapy. J Cardiovasc Electrophysiol. 2008;19(2):133-5. doi:10.1111/j.1540-8167.2007.01032.x.

30. Kitaizumi K, Yukiiri K, Masugata H, Shinomiya K, Ohara M, Takinami H, et al. Positron emission tomographic demonstration of myocardial oxidative metabolism in a case of left ventricular restoration after cardiac resynchronization therapy. Circ J: Off J Jpn Circ Soc. 2008;72(11):1900-3.

31. Kitaizumi K, Yukiiri K, Masugata H, Takinami H, Iwado Y, Noma T, et al. Acute improvement of cardiac efficiency measured by 11C-acetate PET after cardiac resynchronization therapy and clinical outcome. Int J Cardiovasc Imaging. 2010;26(3):285-92. doi:10.1007/ s10554-009-9549-8.

32. Croteau E, Tremblay S, Gascon S, Dumulon-Perreault V, Labbe SM, Rousseau JA, et al. [(11) C]-Acetoacetate PET imaging: a potential early marker for cardiac heart failure. Nucl Med Biol. 2014;41(10):863-70. doi:10.1016/j.nucmedbio.2014.08.006.

33. Tuunanen H, Ukkonen H, Knuuti J. Myocardial fatty acid metabolism and cardiac performance in heart failure. Curr Cardiol Rep. 2008;10(2):142-8. 
34. Knaapen P, Knuuti J, van Rossum AC. The failing heart. N Engl J Med. 2007;356(24):2545. author reply 6.

35. Peterson LR, Soto PF, Herrero P, Mohammed BS, Avidan MS, Schechtman KB, et al. Impact of gender on the myocardial metabolic response to obesity. J Am Coll Cardiol Img. 2008; 1 (4):424-33. doi:10.1016/j.jcmg.2008.05.004.

36. Ciccarelli M, Chuprun JK, Rengo G, Gao E, Wei Z, Peroutka RJ, et al. G protein-coupled receptor kinase 2 activity impairs cardiac glucose uptake and promotes insulin resistance after myocardial ischemia. Circulation. 2011;123(18):1953-62. doi:10.1161/circulationaha.110. 988642.

37. Shirani J, Dilsizian V. Molecular imaging targets of cardiac remodeling. Curr Cardiol Rep. 2009;11(2):148-54.

38. Su H, Spinale FG, Dobrucki LW, Song J, Hua J, Sweterlitsch S, et al. Noninvasive targeted imaging of matrix metalloproteinase activation in a murine model of postinfarction remodeling. Circulation. 2005;112(20):3157-67. doi:10.1161/circulationaha.105.583021.

39. Matusiak N, van Waarde A, Bischoff R, Oltenfreiter R, van de Wiele C, Dierckx RA, et al. Probes for non-invasive matrix metalloproteinase-targeted imaging with PET and SPECT. Curr Pharm Des. 2013;19(25):4647-72.

40. Higuchi T, Bengel FM, Seidl S, Watzlowik P, Kessler H, Hegenloh R, et al. Assessment of alphavbeta3 integrin expression after myocardial infarction by positron emission tomography. Cardiovasc Res. 2008;78(2):395-403. doi:10.1093/cvr/cvn033.

41. Prato FS, Butler J, Sykes J, Keenliside L, Blackwood KJ, Thompson RT, et al. Can the inflammatory response be evaluated using $18 \mathrm{~F}-\mathrm{FDG}$ within zones of microvascular obstruction after myocardial infarction? J Nucl Med: Off Publ Soc Nucl Med. 2015;56(2):299-304. doi:10. 2967/jnumed.114.147835.

42. Thackeray JT, Bankstahl JP, Wang Y, Korf-Klingebiel M, Walte A, Wittneben A, et al. Targeting post-infarct inflammation by PET imaging: comparison of (68)Ga-citrate and (68)Ga-DOTATATE with (18)F-FDG in a mouse model. Eur J Nucl Med Mol Imaging. 2015;42(2):317-27. doi:10.1007/s00259-014-2884-6.

43. Reiter T, Werner RA, Bauer WR, Lapa C. Detection of cardiac sarcoidosis by macrophagedirected somatostatin receptor 2-based positron emission tomography/computed tomography. Eur Heart J. 2015. doi:10.1093/eurheartj/ehv278.

44. Lapa C, Reiter T, Li X, Werner RA, Samnick S, Jahns R, et al. Imaging of myocardial inflammation with somatostatin receptor based PET/CT - A comparison to cardiac MRI. Int J Cardiol. 2015;194:44-9. doi:10.1016/j.ijcard.2015.05.073. 